\title{
Preclinical update on regulation of intracranial pressure in relation to idiopathic intracranial hypertension
}

\author{
Sajedeh Eftekhari* ${ }^{*}$, Connar Stanley James Westgate, Maria Schmidt Uldall and Rigmor Hoejland Jensen
}

\begin{abstract}
Background: Elevated intracranial pressure (ICP) is observed in association with a range of brain disorders. One of these challenging disorders is idiopathic intracranial hypertension (IIH), characterized by raised ICP of unknown cause with significant morbidity and limited therapeutic options. In this review, special focus is put on the preclinical research performed in order to understand the pathophysiology behind ICP regulation and IIH. This includes cerebrospinal fluid dynamics, molecular mechanisms underlying disturbances in brain fluids leading to elevated ICP, role of obesity in $\mathrm{IH}$, development of an $\mathrm{IH}$ model and ICP measurements in rodents. The review also discusses existing and new drug targets for IIH that have been evaluated in vivo.

Conclusions: ICP monitoring in rodents is challenging and different methods have been applied. Some of these methods are invasive, depend on use of anesthesia and only allow short-term monitoring. Long-term ICP recordings are needed to study $\| \mathrm{H}$ but existing methods are hampered by several limitations. As obesity is one of the most common risk factors for $\mathrm{IH}$, a rodent obese model has been developed that mimics some key aspects of $\mathrm{IH}$. The most commonly used drugs for IIH have been evaluated in vivo for their efficacy at lowering ICP in the existing animal models. These studies suggest these drugs, including acetazolamide, might have limited or no reducing effect on ICP. Two drug targets that can impact ICP in healthy rodents are topiramate and a glucagon-like peptide-1 receptor (GLP1R) agonist. However, it remains to evaluate their effect in an IIH model with more precise and valid ICP monitoring system. Therefore, continued evaluation in the preclinical research with refined tools is of great importance to further understand the pathophysiology behind disorders with raised ICP and to explore new drug targets.
\end{abstract}

Keywords: Intracranial pressure, In vivo, Idiopathic intracranial hypertension, Choroid plexus, Cerebrospinal fluid regulation

\section{Introduction}

Intracranial pressure and idiopathic intracranial hypertension

Elevated intracranial pressure (ICP) is observed in association with a range of brain disorders and their underlying pathophysiology is widely unknown. Actually, there is limited insight into the regulatory mechanisms of this essential balance under normal conditions and consequently also a significant lack of specific treatments. In

\footnotetext{
*Correspondence: Sajedeh.eftekhari@regionh.dk
}

Danish Headache Center, Department of Neurology, Glostrup

Research Institute, Rigshospitalet-Glostrup, University of Copenhagen,

Nordstjernevej 42, 2600 Glostrup, Denmark this review, we aim to focus on the preclinical research behind ICP regulation mainly with Idiopathic Intracranial Hypertension (IIH) as a disease model. Further, we aim to discuss the existing and novel drug targets for IIH that have been evaluated in preclinical models.

The regulation of ICP is fundamental for providing a stable environment to enable normal brain function. According to the anatomists Monro and Kellie, ICP is determined by three parameters; the volume of the brain, cerebral blood volume and cerebrospinal fluid (CSF) volume, where cerebral blood volume and CSF are homeostatically controlled and compensate for acute changes in ICP [1]. Several cerebral pathologies of raised ICP exist which have profound consequences for the patients, such 
as: traumatic brain injury (TBI), ischemic stroke, brain tumor, hepatic encephalopathy, hydrocephalus and IIH. $\mathrm{IIH}$ is a rare disease with an incidence of 4.7 per 100,000 in the UK, where the disease predominantly affects females (82\%) [2]. Raised ICP is an obligatory symptom of $\mathrm{IIH}$, thus it is apparent that ICP homeostasis is perturbed in IIH. The diagnosis of IIH eliminates secondary causes of raised ICP, consequently altered cerebral anatomy and altered brain blood volume are unlikely to be causative in IIH. As such, CSF dynamics in IIH must be perturbed, where CSF dynamics are a balance of CSF secretion and drainage $[3,4]$.

\section{CSF secretion}

Humans produce around $500 \mathrm{ml}$ of CSF per day, filling CSF spaces to a volume of $120-150 \mathrm{ml}$, indicating an average secretion rate of around $20 \mathrm{ml} / \mathrm{h}$. A portion of CSF is generated from cerebral interstitial fluid via the ependymal lining of the ventricles and the pia mater, likely through hydrostatic forces. However the majority of CSF is generated via the choroid plexus (CP), organs that reside in the cerebral ventricles and display the characteristic asymmetrical distribution of ion transporters of fluid transporting epithelia (Fig. 1). Although it is clear that the activity of ion transporters such as the $\mathrm{Na}^{+} / \mathrm{K}^{+}$

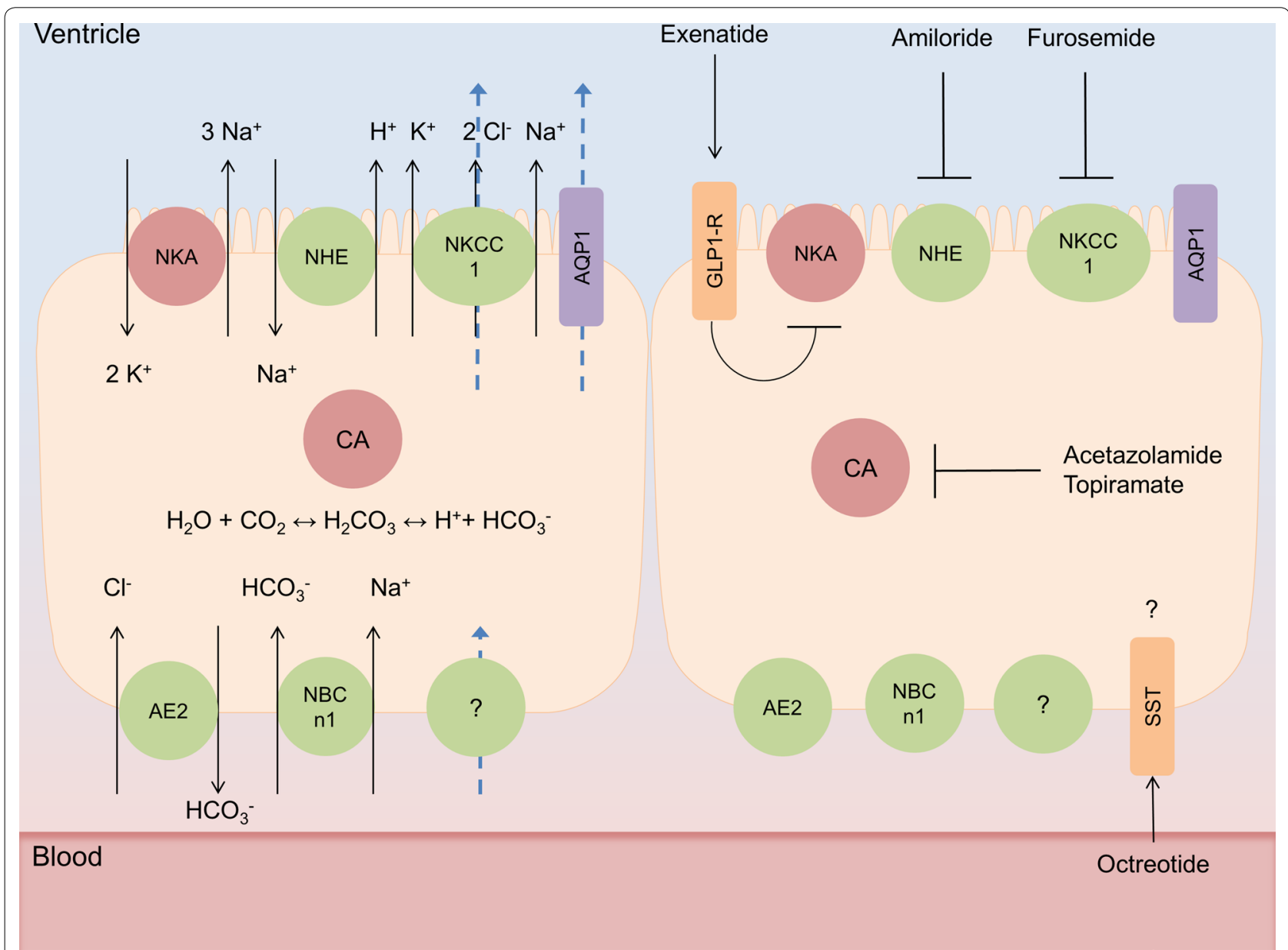

Fig. 1 CSF secretion modulation at the choroid plexus. Simplified schematics of choroid plexus epithelial (CPe) cells. (Left cell) CSF secretion at CPe cells, whereby the activity of carbonic anhydrase (CA) generates carbonic acid which dissociates to a proton and a bicarbonate ion, these drive the sodium/hydrogen exchanger (NHE) and anion exchanger (AE2) respectively, transporting sodium and chloride ions into CPe cells. Additionally the basolateral sodium bicarbonate transporter (NBCn1) transports bicarbonate and sodium ions into the cell. These provide the ionic gradients to drive both the $\mathrm{Na}^{+} / \mathrm{K}^{+}$ATPase and the NKCC1 channel to transport sodium into the ventricular spaces, this facilitates the osmosis of water via aquaporin 1 (AQP1). Furthermore the action of NKCC1 independently draws water from the cytosol to the ventricular space. The mechanisms of basolateral water transport remain unelucidated. Blue arrows represent the movement of water. CPe cell to the right represents current and proposed drug targets for modulating CSF secretion at the choroid plexus where the majority directly modifies the transport or generation of ions. The exceptions lie with somatostatin receptor (SST) agonist octreotide whose function and effect on ICP are unclear, and glucagon like peptide 1 receptor (GLP-1R) agonist exenatide which inhibits $\mathrm{Na}^{+} / \mathrm{K}^{+}$ATPase actity 
ATPase and the $\mathrm{Na}^{+}-\mathrm{K}^{+}-2 \mathrm{Cl}^{-}-1$ cotransporter (NKCC1) are fundamental in CSF secretion at the $\mathrm{CP}$, and are targeted clinically to reduce ICP (Fig. 1), the mechanisms underlying the transport of water at the $\mathrm{CP}$ are controversial $[5,6]$. It has been hypothesized that CSF secretion at the $\mathrm{CP}$ is predominantly driven by osmosis, facilitated by the expression of the water channel Aquaporin 1 (AQP1). However, evidence suggests that this is not the case. The $\mathrm{CP}$ is relatively impermeable to water, which is likely explained by the predominantly apical expression of AQP1 on CP, preventing osmosis [7-9]. Indeed AQP1 knockout mice do not ameliorate CSF secretion [10]. Additionally the CP secretes CSF against an osmotic gradient, further demonstrating that osmosis is likely not the primary driver of CSF secretion [11]. This secretion independent of osmosis is mediated by solutemediated water co-transport, via the NKCC1 transporter, which contributes to roughly $50 \%$ of CSF secretion in mice [6]. Although this accounts for the majority of water transport at the apical CP membrane, there is little understanding as to how water is transported across the basolateral membrane of the $\mathrm{CP}$, although it is likely mediated via solute mediated water co-transport [12].

\section{CSF drainage}

Where CSF is produced it must be drained in such a manner that is homeostatically maintained to prevent aberrant alterations in ICP. Although the mechanisms underlying the homeostasis and molecular aspects of CSF drainage have not been elucidated, the structures where CSF drainage occurs are clearly defined. The arachnoid granulations (AG) of the superior sagittal sinus are thought to drain CSF directly into the venous system [13]. The precise mechanism for CSF drainage at the AG is unknown and the contribution of AG to CSF drainage is unknown. It is hypothesized to be facilitated through either paracellular movement of water or the vacuolisation of CSF by the capsule cells of the AG [14]. However the lack of AG in rodents suggests that other modalities for CSF drainage exist.

It has been hypothesised that CSF can be drained via perivascular spaces that penetrate the parenchyma, termed glymphatics, in an Aquaporin-4 (AQP4) dependent manner [15]. This glymphatic drainage could be aided via the proposed trans-ependymal CSF flow from the ventricles to the parenchyma [16]. Additionally, two distinct branches of the lymphatic system have been demonstrated to drain CSF. The lymphatics of the nasal cavity have been demonstrated to drain CSF through the cribriform plate in a variety of mammals including humans and non-human primates [17, 18]. Additionally, dural lymphatics have the capability to drain CSF and that damage to them reduces CSF flow and drainage $[19,20]$.

\section{Regulation of ICP and IIH}

There are currently a limited number of studies that assess CSF dynamics in IIH. Several studies utilizing small cohorts of IIH patients identified an increased CSF flow rate through the cerebral aqueduct, indicating increased CSF secretion [21-23]. Studies utilizing isotope cisternography suggest that IIH patients have increased resistance to CSF drainage, however these findings are not universal across IIH patients and could be confounded by increased venous sinus pressure [24-26].

Histological data from cortical biopsies of IIH patients showed increased AQP4 expression at astrocyte end feet, a constituent of the glymphatic drainage. This is suggestive of an altered state of CSF clearance via the glymphatic system [27]. Furthermore this study identifies that IIH brains have astrogliosis, perhaps explaining previous findings that IIH patients have larger ICP wave forms compared to headache controls, which indicate reduced parenchymal compliance $[27,28]$. In a recent study from the same group, they demonstrated dysfunction of the blood-brain barrier (BBB) by measuring the extent of extravasated fibrinogen in IIH patients compared to reference material [29]. This study suggests that there may be leakage of BBB in IIH patients [29]. Further research is needed to evaluate the possible changes of BBB in IIH patients and what might cause the leakage.

Although it is apparent that ICP and in particular CSF dynamics are altered in $\mathrm{IIH}$, the current literature fails to elucidate conclusively whether IIH patients have CSF hypersecretion, reduced CSF drainage or a combination of these factors. Furthermore the studies do not address the etiology of the alterations they describe, consequently further studies are required.

\section{ICP dynamics in IIH}

The gold standard for measuring ICP in patients is by using an intracranial probe however, this requires neuro-surgical intervention with risk of infections. Lumbar puncture (LP) opening pressure measured during an LP is less invasive however, the obtained ICP values are less accurate than the gold standard method, and can only provide a short-term pressure reading during the procedure. There are some LP measurement methods that have been shown to be comparable to intraparenchymal ICP recordings [30-32]. The LP opening pressure is a common procedure in the diagnosis of IIH but is not always standardized. According to the latest consensus, the diagnostic criteria mandate a cut-off opening pressure of $>25 \mathrm{~cm}$ CSF $(18.3 \mathrm{mmHg})$ for diagnosing IIH [4]. However, this absolute value for IIH diagnosis is widely discussed as most clinicians experience a 'grey zone' between $25 \mathrm{~cm} \mathrm{CSF}$ and $30 \mathrm{~cm}$ 
CSF, which may not be pathological [33]. Further, it is also recognized in the consensus that this cut-off value is based on a single LP measurement and it should be recognized that there is a diurnal and wide variation in CSF pressure in patients [4]. It also highly debated if the LP opening pressure may not provide the true steady-state pressure because of normal fluctuations in ICP. Although mean ICP may decrease with responsive treatments, it has been shown that IIH patients still had raised mean ICP wave amplitude compared to controls, suggesting that the pulsatile ICP may be more relevant than the static ICP in the diagnostic setting for patients with IIH [28]. Another issue is that there are no true reference values for ICP in healthy humans. In one study, ICP was investigated in healthy elderly people (60-82 years) with no psychiatric or neurologic disorders and these values could be used as reference values in the elderly [34]. Otherwise, what is considered to be normal values of ICP is based on examinations in patients needing ICP monitoring due to suspected disturbance in ICP. In some clinical studies, a control group of patients considered to be "pseudonormal" have been used in order to better understand the ICP values in humans. From these studies, the effect of body posture on ICP differed between healthy and patients with conditions with elevated ICP, where in normal human physiology patients appeared to have more tightly regulated ICP when switching body posture $[35,36]$. ICP reference values are currently estimated to be $7-15 \mathrm{mmHg}$ in a horizontal position, however these values can be lower and negative and should be considered to be normal (supine position, mean ICP $0.5 \mathrm{mmHg}$; vertical position, mean ICP $-3.7 \mathrm{mmHg}$ ) [37]. Further, it has also been demonstrated that the "pseudonormal" group of patients had higher night time ICP compared to day time during $24 \mathrm{~h} \mathrm{ICP}$ monitoring [38]. In addition, the authors reported decrease of ICP with age across all ages [38]. The remaining question is if these values might be similar in healthy subjects. Since ICP monitoring in healthy subjects is ethically unacceptable, a study evaluating ICP regulation with detailed waveform analysis in normal rodents would be of great value.

In rodents, ICP values have been reported to vary between 2 and $8 \mathrm{mmHg}$ with a mean value around $6 \mathrm{mmHg}[39,40]$. In animal models with raised ICP such as hydrocephalus, TBI and stroke, ICP is raised to $10-30 \mathrm{mmHg}[39,41,42]$. The question is to what extent ICP should be raised in an animal model of IIH. As an IIH model should not cause severe damage, we predict that mean ICP should be above 6-7 $\mathrm{mmHg}$ but probably not extending as high as in the severe cerebral trauma models.

\section{IIH pathophysiology}

As mentioned earlier, IIH is a challenging disease with increased ICP of unknown aetiology and was previously called benign intracranial hypertension or pseudotumor cerebri. The most disabling symptoms are chronic headache, impaired vision due to optic nerve compression and cognitive impairment [43-45]. IIH occurs mainly in young female individuals, 3.5 in 100,000 in the general population, but the incidence is rapidly increasing in the wake of the global obesity epidemic, with up to 20 in 100,000 in the obese population [3, 46-48]. The higher incidence and increased awareness may have improved the visual prognosis, whereas disabling headaches and cognitive dysfunction persist and lifelong disability may be the result $[45,49,50]$. Recent clinical evidence suggests the involvement of hormones, androgens and glucocorticoids in IIH pathophysiology [3, 51, 52]. As many IIH patients are obese, they might also have increased risk factors for cardiovascular conditions. In one study it was shown that $56 \%$ of the $\mathrm{IIH}$ patients had hypertension [53]. However, control patients were not included and the hypertension might have been due to obesity. In a recent large matched cohort study, the risks of cardiovascular disorders were evaluated in women with IIH compared to controls matched on BMI and age [54]. The risk of heart failure, ischemic heart disease, stroke/ transient ischemic attack (TIA), type 2 diabetes, and hypertension was shown to be increased in women with IIH (30). For hypertension, the crude incidence rate was 14.1 per 1000 person-years in women with $\mathrm{IIH}$ and 9.2 per 1000 person-years in those without IIH (30). The underlying mechanisms for these risk factors need to be evaluated. Interestingly, it has been suggested that hypertension may alter CP dynamics affecting CSF production and causing BBB alterations [55]. Preclinical studies have demonstrated that hypertensive rats have variations in their CSF composition that could be due to CSF dysfunction, which may lead to blood-CSF barrier disruption [56]. Furthermore, it has been shown that hypertensive rats have increased CSF secretion rate and $\mathrm{CP}$ blood flow [57]. Therefore, it remains to be clarified if and how hypertension may affect the CSF dynamics in IIH patients.

As the molecular regulation of CSF is not yet fully understood, there is a lack of understanding for many pathological conditions associated with abnormal CSF dynamics. Hence, diseases involving elevated ICP are generally poorly understood and managed, due to the lack of specific targeted treatment options. Medical interventions for IIH range from dietary therapy (weight loss) to diuretics and surgical CSF diversion [3]. In IIH patients with rapidly declining vision, CSF diversion surgery may be necessary. Thereby, the majority of 
the patients receive medications that may reduce CSF secretion and consequently reduce ICP. However, all the interventions for IIH are non-specific and hampered by side effects. The 2015 Cochrane review concluded there was insufficient evidence to determine which treatments are potentially beneficial in IIH [58]. Therefore, there remains an unmet medical need for effective treatments of IIH. This highlights the need for preclinical research using animal models to increase the understating of the pathophysiology behind IIH and to explore novel drug targets.

\section{Role of obesity in IIH}

IIH has a prominent association with both the female gender and obesity as $90 \%$ of patients with IIH are obese $[3,48,59]$. The risk of IIH also increases with increasing BMI. The greater amount of weight gain the year before symptom onset resulted in a greater risk of IIH [46]. Thereby, weight loss has been suggested as effective treatment strategy as it can lower ICP and improves some IIH symptoms [60-62]. However, typically weight loss is not maintained, meaning IIH symptoms return. Bariatric surgery has been suggested as a therapy option for IIH patients but these studies have been done in smaller patients groups without proper controls, so more studies are needed here $[63,64]$. A randomized controlled trial of bariatric surgery in IIH patients has been started with the aim to compare two methods of weight loss, bariatric surgery and a dietary program, to see which offers the most effective sustainable treatment for IIH [65]. The trial is expected to be completed in 2022 (ClinicalTrials. gov, NCT02124486).

There is also a strong association between abdominal fat deposition and health outcomes consequently adipose distribution in patients with IIH may be of relevance [66]. It has been shown that preferential lower body fat accumulation occurs in IIH patients using waisthip ratios [67]. In a more recent study the gold standard dual-energy X-ray absorptiometry (DEXA) scanning technique was used to evaluate fat mass and distribution in IIH patients. In this study the authors found instead that IIH patients have a similar centripetal distribution of fat mass to patients with simple obesity [68]. These results raise the question whether it is the type of adipose tissue or its location that is of relevance for IIH. Adipose tissue functions as an endocrine organ, secreting a myriad of factors including proinflammatory cytokines, chemokines and adipokines [66, 69]. Therefore, hormone secretion from adipose tissue may be implicated in IIH. As obesity is the most common risk factor for $\mathrm{IIH}$, the impact of obesity on ICP in rodents has been evaluated by our group and is discussed below.

\section{Development of a rodent IIH model}

Currently there are very few animal models with elevated ICP and they are associated with the induction of severe cerebral traumas such as subarachnoid hemorrhage, TBI, brain tumors, kaolin induced hydrocephalus and cerebral ischemia [39, 42, 70-73]. Development of an intracranial hypertension model without causing severe damage would be a valuable tool to increase our knowledge regarding the molecular regulation of CSF and disorders affecting the CSF production/regulation such as IIH. A model for IIH could improve the knowledge regarding the pathophysiology of this disorder as well as the molecular mechanisms behind elevated ICP in other conditions. So far only one model has been developed that mimics some aspects of IIH [74]. Since there is a strong association between obesity and $\mathrm{IIH}$, a model for obesity-induced IIH has been developed [74]. Zucker rats have been used as an obesity model with a mutation in the leptin receptor gene causing hyperphagia [75, 76]. Our group has demonstrated that the Zucker rats have higher ICP compared to lean-rats, suggesting that obesity may increase ICP [74]. At the end of the study, 28 days, the Zucker rats had an average of $40 \%$ higher ICP with the tendency of the ICP to increase in parallel with increasing BMI. Interestingly, mRNA and protein expression of AQP1 in CP of the obese rats were elevated compared to lean rats however no differences in the expression of NA/K ATPase alpha 1 expression was observed [74]. Physiological factors known to potentially influence ICP such as mean arterial blood pressure (MABP), arterial blood gases, serum retinol and retinol binding protein 4 (RBP4) levels were investigated. The authors found no differences in these parameters between the obese rats and lean rats supporting that the increase in ICP was attributed to the obesity. Although the Zucker rats developed higher ICP, the question is if this a sufficient elevation to mimic the pathologically elevated ICP observed in IIH. Further, the obesity observed in IIH patients is hypothesized to be diet-induced since weight loss is associated with improvement in some of the IIH symptoms. Therefore, it will be of great interest to study ICP levels in diet-induced obese rats, which share many characteristics with the common form of human obesity. In addition, it will be of great importance for a robust IIH model to also mimic other clinically relevant IIH symptoms such as papilledema and headache. Further, researchers suggest that hormonal and metabolic factors play an essential role in the development of $\mathrm{IIH}$ and these co-factors also needs to be evaluated in animal models for IIH $[3,51,66]$. A recent study has also highlighted the role of androgen excess in IIH patients showing that female IIH patients had increased testosterone in both serum and CSF [52]. The in vitro data demonstrated 
that testosterone is able to enhance the activity of $\mathrm{Na}^{+} /$ $\mathrm{K}^{+}$-ATPase at the $\mathrm{CP}$, suggesting that testosterone may modulate CSF secretion [52]. It remains to evaluate the effects of testosterone in vivo to elucidate its impact on ICP and as a driver for IIH.

\section{ICP measurements in animal research}

Another fundamental factor in the development of an IIH animal model is the ability to perform long-term ICP measurements in rodents. ICP measurements are widely used for diagnostic purposes and to inform treatment options for conditions with raised ICP such as IIH. However, the invasive nature of performing ICP monitoring in humans limits clinical research. Thereby, there is a great need of consistent and precise ICP recording in animal models, where ICP can be measured across the day, in response to a drug and during disease development. However, it has been very challenging to measure ICP accurately in animal models due to the lack of refined equipment designed specifically to measure ICP in rodents. Various locations and techniques for measuring ICP have been investigated such as epidural, subdural, ventricular cisterna magna placement using a cannula, fluid-filled catheter or fiber-optic pressure transducers [77-86], summarized in Table 1. Lumbar cannulation has also been investigated in rodents [86, 87]. The intraventricular technique in the preclinical setting is very invasive and causes severe complications such as infections and degeneration of the cerebral tissue, so only short-term monitoring is possible. Therefore, subdural and epidural cannulations are mostly used for ICP measurements in animal models. We have developed a novel method for long-term monitoring of ICP in rats from epidural space using fluid-filled catheter [40]. This study demonstrated that the epidural ICP recordings correlated exceptionally well with ventricular ICP with no complications as observed with the ventricular probes [40]. In the rats implanted with ventricular ICP probes, the probes lost patency and many of the animals developed symptoms of neurological malfunction, infections and/or displayed general signs of illness. At post mortem brain examination, hydrocephalus was observed in the rats with the ventricular probes [40]. We found that the epidural probes were less invasive with no tissue damage. These results suggest that the ventricular cannulation for ICP recordings may not be suitable for research purposes investigating molecular changes in ICP and CSF production. This study is also the longest ICP monitoring performed in rats, for up to 59 days. However, ICP recordings could not be performed daily and therefore the ICP recordings were performed on selected days with a total of 6 recordings.
Table 1 Overview of preclinical studies using different methods to measure ICP in rat models

\begin{tabular}{|c|c|c|c|}
\hline Refs. & Measuring site & Measuring period & Method \\
\hline [122] & Cisterna magna $^{a}$ & 4 days & Fluid-filled system \\
\hline [83] & Cisterna magna $^{a}$ & Unknown & Fluid-filled system \\
\hline [84] & Cisterna magna $^{a}$ & $1.5 \mathrm{~h}$ & Fluid-filled system \\
\hline [123] & $\begin{array}{l}\text { Cisterna magna } \\
\text { Ventricular }^{\mathrm{a}}\end{array}$ & $1 \mathrm{~h}$ & Fluid-filled system \\
\hline$[40]$ & $\begin{array}{l}\text { Ventricular and } \\
\text { epidural }^{\mathrm{a}}\end{array}$ & 59 days & Fluid-filled system \\
\hline [81] & Ventricular & Unknown & Fluid-filled system \\
\hline [124] & Ventricular & 28 days & Fluid-filled system \\
\hline [94] & $\begin{array}{l}\text { Subarachnoid } \\
\text { space }^{\mathrm{a}}\end{array}$ & $4 \mathrm{~h}$ & Fluid-filled system \\
\hline [87] & $\begin{array}{l}\text { Lumbar } \\
\text { cannulation }^{\mathrm{a}}\end{array}$ & $25 \mathrm{~h}$ & Fluid-filled system \\
\hline [125] & $\begin{array}{l}\text { Lumbar } \\
\quad \text { cannulation }{ }^{a}\end{array}$ & $25 \mathrm{~h}$ & Fluid-filled system \\
\hline [125] & Subdural ${ }^{\mathrm{a}}$ & 7 days & Fluid-filled system \\
\hline [77] & Epidural $^{a}$ & $6 \mathrm{~h}$ & Fluid-filled system \\
\hline [126] & Epidural $^{a}$ & $1 \mathrm{~h}$ & Fluid-filled system \\
\hline [123] & Parenchyma ${ }^{a}$ & $1 \mathrm{~h}$ & Fiber-optic transducer \\
\hline [86] & Parenchyma ${ }^{a}$ & 14 days & Fiber-optic transducer \\
\hline [127] & Parenchyma & $20 \mathrm{~h}$ & Fiber-optic transducer \\
\hline [85] & Parenchyma ${ }^{a}$ & $3 \mathrm{~h}$ & Fiber-optic transducer \\
\hline [88] & Ventricular $^{\mathrm{a}}$ & 7 days & Telemetric device \\
\hline [128] & Ventricular & 2-10 days & Telemetric device \\
\hline [78] & Epidural & 5 days & Telemetric device \\
\hline [41] & Ventricular ${ }^{b}$ & 6 days & Telemetric device \\
\hline [90] & Ventricular ${ }^{\mathrm{b}}$ & 5 days & Telemetric device \\
\hline [39] & Subdural ${ }^{b}$ & 28 days & Telemetric device \\
\hline
\end{tabular}

${ }^{a}$ Indicates that the rats where anesthetized/sedated during ICP measurements

b Indicates continuous 24/7 ICP measurements

Although the implementation of epidural ICP recording using fluid-filled systems has been a major improvement for measuring ICP in rodents, this method has some limitations. In this method the transducer is not permanently implanted, which prevents the possibility of continuous ICP recordings over larger time intervals. Furthermore, this ICP method as the others depends on repeated use of anesthesia/sedation before each recording to immobilize the animals which are additional cofounders affecting ICP. Additionally, the fluid-filled systems can develop air bubbles, resulting in false ICP values. Fiber-optic pressure transducers have been used to avoid these problems, however, it has only been developed for animals under anesthesia [79]. Telemetry devices using fluid-filled systems were developed in order to measure small changes in ICP and with the aim to develop a system for freely moving animals. This kind of telemetry has been used in rodents however ICP monitoring in freely moving rats was limited to $2-7$ days $[78,88,89]$. 
Recently, telemetric probes with specific ICP transducers have been developed to measure ICP continuously in freely moving rats (Kaha Sciences) [39]. This has a number of clear advantages compared to other available options in the field; it allows long-term recordings under conditions unhindered by anesthesia or restraint. So far this system has only been used in few studies, one in healthy male rats with continuous ICP monitoring for 28 days and two in a TBI model with ICP continuously monitored for 5-6 days [39, 41, 90]. Since this system does not require any use of anesthesia/sedation for ICP recording, it may be very useful to study drug effects without any impact from additional confounders. It is important to be aware that in all the in vivo drug studies discussed below, anesthesia/sedation was used in order to measure ICP and the recordings were not performed continuously.

\section{Drug targets for IIH Acetazolamide}

In the management of $\mathrm{IIH}$, the focus is on reducing the elevated ICP by pharmacological therapy. Given that IIH patients often suffer from visual disturbances and headache, management of IIH has been focused on preserving vision and reducing headache morbidity [4]. In this case, acetazolamide is the most commonly used drug for treatment of IIH. This drug is a carbonic anhydrase (CA) inhibitor that is believed to reduce CSF secretion and ICP via action on the $\mathrm{CP}$ by reducing ion transport consequently water across CP (Fig. 1). It has been suggested that acetazolamide may decrease CSF secretion by $55 \%$ in rats [91] and at similar rates in rabbits [92]. While some clinical studies have demonstrated a beneficial effect in IIH, it has limited efficacy, poor tolerability, and unresolved target mechanisms. Therefore, it is of great value to study the effect of this drug in preclinical models to understand its mechanisms and possible effects. In healthy rats, we have shown that a single high dose of acetazolamide (200 mg, given i.p.) lowered ICP and modulated the CSF secretion pathway [93]. Interestingly, we found that AQP1 and $\mathrm{Na} / \mathrm{K}$ ATPase protein were increased in the membrane of CP epithelial cells, which could be a compensatory mechanism for the reduced ICP. In support, an older study also demonstrated that acetazolamide given as intravenous infusion in rats caused a reduction in ICP [94]. However, another study showed that intra-arterial injections of acetazolamide reduced ICP, whereas intraventricular injection had no effect [95]. Thus it seems that the administration route and dose of acetazolamide is important for studying its effect on ICP. In a recent study, a clinically relevant dose of acetazolamide was tested in rats via different administration routes [96]. The low dose of acetazolamide $(103.3 \mathrm{mg} / \mathrm{kg})$ that was equivalent to a single human dose $(1 \mathrm{~g})$ and a high dose $(413.4 \mathrm{mg} / \mathrm{kg})$ equivalent to a human daily dose (4 g) were administered either subcutaneously or orally. Neither the low nor the high dose of acetazolamide significantly lowered ICP [96]. Using the most clinically relevant delivery route for acetazolamide, oral administration, the drug lowered blood $\mathrm{pH}$ and induced diuresis in the rats, however it did not change ICP [96]. In this study, the authors used $4 \% \mathrm{NaCl}$ as appropriate vehicle control as hypertonic solutions can lower ICP. This might explain the conflicting results from previous studies. In support of this study, in a rodent stroke model, acetazolamide $(50 \mathrm{mg} / \mathrm{kg})$ given i.p. improved the pathological ICP spikes but it did not impact in the mean ICP levels or the outcome [97]. However, in all these studies only a single dose of acetazolamide was examined. Therefore, it is of great importance to examine if repeated clinical doses of acetazolamide might lower ICP as IIH patients often need repeated dosing of acetazolamide. In another condition with raised ICP, treatment with acetazolamide had no effect on clinical signs or ventricular volume in dogs with internal hydrocephalus [98]. Importantly, in clinical studies, treatment with acetazolamide resulted in symptom improvements such as visual field function in IIH patients with mild visual loss $[99,100]$. In the animal studies, only the direct effects on ICP were studied, as a proper IIH animal model with related symptoms is missing. Therefore, it remains to investigate the effects of acetazolamide in a pathological condition mimicking $\mathrm{IIH}$ in vivo. Although acetazolamide is the most common used drug for IIH, the support for its efficacy on lowering ICP is inconclusive. As many patients do not tolerate the drug due to all its severe side effects, it is even more important to further evaluate the effect of this drug and its use for IIH.

\section{Topiramate}

Topiramate was originally used for epilepsy treatment and as a migraine prophylactic drug [101, 102]. Topiramate has many mechanisms of action via activity on four protein complexes that are regulated by protein kinase phosphorylation: voltage-gated sodium channels, high voltage-gated calcium channels, GABA receptors, and AMPA/kainate receptors [102]. In addition, topiramate is a CA inhibitor similar to acetazolamide (Fig. 1) and has therefore become of interest for IIH treatment. Topiramate is of interest for IIH headache treatment, given that topiramate is an effective migraine prophylactic and that many IIH patients suffer from severe headache. In addition, topiramate can induce favorable and welcomed weight loss which is of benefit for treating $\mathrm{IIH}$ patients [103]. There are some clinical case studies that have shown efficacy of topiramate for IIH symptoms 
[104-107]. Compared to acetazolamide, topiramate has higher carbonic anhydrase isoform specificity and increased lipophilic nature, which suggest better pharmacological activity than acetazolamide. However, in an open label study, it was shown that topiramate improved IIH symptoms but no differences were found compared to acetazolamide treatment [108]. In a recent preclinical study, it was however shown that topiramate significantly lowered ICP in healthy rats while acetazolamide did not reduce ICP [96]. Topiramate was tested at both clinical low and high doses, which lowered ICP levels by $32 \%$ and $21 \%$ respectively in healthy rats [96]. It remains to elucidate the effect of this drug on ICP in animal models with raised ICP and evaluate its effect of daily dosing as performed in the clinical studies. Although topiramate might have beneficial effects for IIH patients, this drug causes serious side effects such as cognitive impairment, insomnia, paraesthesia, fatigue and anxiety. This drug may therefore not be a better treatment option for $\mathrm{IIH}$ than acetazolamide.

\section{Amiloride and furosemide}

Diuretic agents have long been known to reduce CSF secretion and have therefore been regarded as a treatment option for IIH (Fig. 1). One of these agents is furosemide, which blocks the cotransporter NKCC1 on CP epithelial cells. Furosemide has shown to reduce CSF secretion in various species [92, 109-111]. Furosemide has usually been used in combination with mannitol, where the combination has shown to reduce ICP [112, 113]. It has also been tested in combination with $3 \%$ hypertonic saline which reduced ICP in patients with $\mathrm{ICP}>20 \mathrm{mmHg}$ [114]. A rat study showed that furosemide alone did not affect plasma osmolality or brain water content at different doses, however it enhanced the effect of mannitol with greater reduction of brain water content [115]. When furosemide was given alone at high dose or low dose, this drug did not significantly reduce ICP in rats [96]. Another diuretic agent that is able to reduce CSF secretion is amiloride which inhibits the $\mathrm{Na}^{+} / \mathrm{H}^{+}$ exchanger and/or $\mathrm{Na}^{+}$channels on the $\mathrm{CP}$ epithelial cells $[116,117]$. One study has shown that amiloride reduced ICP in experimental brain edema in rats [118]. However, another study in healthy rats showed that amiloride and furosemide did not change ICP [96]. Clinical studies evaluating the efficacy of furosemide or amiloride for the treatment of IIH do not exist.

\section{Octreotide}

Octreotide is a synthetic somatostatin analogue and a potent inhibitor of growth hormone. Two uncontrolled clinical studies have shown its efficacy for IIH treatment $[119,120]$. In an in vivo study in rats a single dose of octreotide had no effect on ICP [96]. However, in the clinical studies, octreotide was given daily to IIH patients during the first months following diagnosis which might be necessary to significantly reduce ICP. Therefore, it will be of great interest to study repeated dosing of octreotide in animal studies.

\section{GLP-1R agonists}

Glucagon-like peptide-1 receptor (GLP-1R) agonists are used to treat diabetes and promote weight loss. Due to its ability to affect fluid homeostasis in the kidney, we investigated if the GLP-1R agonist, exendin-4, could modulate CSF secretion and reduce ICP in rats [42]. This study demonstrated expression of GLP-1R in human and rat $\mathrm{CP}$, and its ability to reduce $\mathrm{Na}^{+}$- and $\mathrm{K}^{+}$-dependent adenosine triphosphatase activity in cell cultures. Subcutaneous injections with exendin- 4 showed a reduction in ICP in both healthy and hydrocephalic rats [42]. Importantly, a single subcutaneous injection of exendin-4 maintained lower ICP for $24 \mathrm{~h}$. These results suggest that GLP-1R agonists may provide an alternative treatment for raised ICP conditions. It will be of great importance to investigate the effect of exendin-4 in an IIH animal model as the pathophysiology is very different from hydrocephalus. In another study it was shown that treatment with the GLP-1 analogue, Liraglutide, significantly reduced cerebral edema after experimental TBI [121]. Taken together, a clinical study investigating the effect of GLP-1R agonists on ICP in humans is highly needed.

\section{Conclusions}

The role of obesity on ICP regulation has been evaluated in vivo and lead to the first animal model mimicking some aspects of IIH. However, a refined model is needed to further investigate the mechanism behind IIH and also to provide valuable new knowledge regarding both regulation and dysregulation of CSF and ICP dynamics. The most used drugs in the management of IIH have been evaluated in rodents and although with some limitations, some of these are not efficient for lowering ICP. However, their effect on IIH-related symptoms such as visual outcome and headache has not been evaluated in animal models. Preclinical research suggests a GLP-1R agonist as a novel drug target for elevated ICP which needs to be further evaluated. Furthermore, a novel ICP monitoring system has been developed for long-term ICP monitoring in freely moving animals, which is a prerequisite to resolve the molecular origin of IIH-elevated ICP and to evaluate drug targets. In conclusion, preclinical investigations including the development of adequate in vivo models are warranted in order to increase our understanding in IIH pathophysiology and to explore novel drug targets able to reduce ICP. 


\begin{abstract}
Abbreviations
AG: arachnoid granulations; AQP1: aquaporin-1; AQP4: aquaporin-4; AQPs: aquaporins; BBB: blood-brain barrier; CA: carbon anhydrase; CNS: central nervous system; CSF: cerebrospinal fluid; CP: choroid plexus; CPe: CP epithelial; CAMP: cyclic adenosine monophosphate; GLP-1R: glucagon-like peptide-1 receptor; IIH: idiopathic intracranial hypertension; i.p.: intra peritoneal; ICP: intracranial pressure; MABP: mean arterial blood pressure; RBP4: retinol binding protein 4; TBI: traumatic brain injury.
\end{abstract}

\section{Acknowledgements}

None.

\section{Authors' contributions}

SE and RHJ have made the outline of the review. SE, RHJ, CSJW and MSU have written the manuscript. All authors read and approved the final manuscript.

\section{Funding}

The Candys Foundation and Lundbeck foundation (Grant nr 276).

\section{Availability of data and materials}

Not applicable.

Ethics approval and consent to participate

Not applicable.

\section{Consent for publication}

Not applicable.

\section{Competing interests}

The authors declare that they have no competing interests.

Received: 9 August 2019 Accepted: 13 November 2019 Published online: 26 November 2019

\section{References}

1. Kim DJ, Czosnyka Z, Kasprowicz M, Smieleweski P, Baledent O, Guerguerian $\mathrm{AM}$, et al. Continuous monitoring of the Monro-Kellie doctrine: is it possible? J Neurotrauma. 2012;29(7):1354-63.

2. Mollan SP, Aguiar M, Evison F, Frew E, Sinclair AJ. The expanding burden of idiopathic intracranial hypertension. Eye. 2019;33(3):478-85.

3. Mollan SP, Ali F, Hassan-Smith G, Botfield H, Friedman DI, Sinclair AJ. Evolving evidence in adult idiopathic intracranial hypertension: pathophysiology and management. J Neurol Neurosurg Psychiatry. 2016;87(9):982-92.

4. Mollan SP, Davies B, Silver NC, Shaw S, Mallucci CL, Wakerley BR, et al. Idiopathic intracranial hypertension: consensus guidelines on management. J Neurol Neurosurg Psychiatry. 2018;89(10):1088-100.

5. Pollay M, Hisey B, Reynolds E, Tomkins P, Stevens FA, Smith R. Choroid plexus $\mathrm{Na}^{+} / \mathrm{K}^{+}$-activated adenosine triphosphatase and cerebrospinal fluid formation. Neurosurgery. 1985;17(5):768-72.

6. Steffensen AB, Oernbo EK, Stoica A, Gerkau NJ, Barbuskaite D, Tritsaris K, et al. Cotransporter-mediated water transport underlying cerebrospinal fluid formation. Nat Commun. 2018;9(1):2167.

7. Praetorius J. Water and solute secretion by the choroid plexus. Pflugers Arch. 2007:454(1):1-18.

8. Praetorius J, Nielsen S. Distribution of sodium transporters and aquaporin-1 in the human choroid plexus. Am J Physiol Cell Physiol. 2006;291(1):C59-67.

9. Speake T, Freeman LJ, Brown PD. Expression of aquaporin 1 and aquaporin 4 water channels in rat choroid plexus. Biochem Biophys Acta. 2003;1609(1):80-6.

10. Oshio K, Watanabe H, Song Y, Verkman AS, Manley GT. Reduced cerebrospinal fluid production and intracranial pressure in mice lacking choroid plexus water channel aquaporin-1. FASEB J. 2005;19(1):76-8.

11. Heisey SR, Held D, Pappenheimer JR. Bulk flow and diffusion in the cerebrospinal fluid system of the goat. Am J Physiol. 1962;203:775-81.
12. MacAulay N, Zeuthen T. Water transport between CNS compartments: contributions of aquaporins and cotransporters. Neuroscience. 2010;168(4):941-56.

13. Cushing $\mathrm{H}$. The third circulation and its channels. Lancet Neurol. 1925;206:851-7.

14. Pollay M. The function and structure of the cerebrospinal fluid outflow system. Cerebrospinal Fluid Res. 2010;7:9.

15. Iliff JJ, Wang M, Liao Y, Plogg BA, Peng W, Gundersen GA, et al. A paravascular pathway facilitates CSF flow through the brain parenchyma and the clearance of interstitial solutes, including amyloid beta. Sci Transl Med. 2012;4(147):147ra11.

16. Casaca-Carreira J, Temel Y, Hescham SA, Jahanshahi A. Transependymal cerebrospinal fluid flow: opportunity for drug delivery? Mol Neurobiol. 2018:55(4):2780-8.

17. Johnston M, Zakharov A, Papaiconomou C, Salmasi G, Armstrong D. Evidence of connections between cerebrospinal fluid and nasal lymphatic vessels in humans, non-human primates and other mammalian species. Cerebrospinal Fluid Res. 2004;1 (1):2.

18. Walter BA, Valera VA, Takahashi S, Ushiki T. The olfactory route for cerebrospinal fluid drainage into the peripheral lymphatic system. Neuropathol Appl Neurobiol. 2006;32(4):388-96.

19. Aspelund A, Antila S, Proulx ST, Karlsen TV, Karaman S, Detmar M, et al. A dural lymphatic vascular system that drains brain interstitial fluid and macromolecules. J Exp Med. 2015;212(7):991-9.

20. Da Mesquita S, Louveau A, Vaccari A, Smirnov I, Cornelison RC, Kingsmore KM, et al. Functional aspects of meningeal lymphatics in ageing and Alzheimer's disease. Nature. 2018:560(7717):185-91.

21. Akay R, Kamisli O, Kahraman A, Oner S, Tecellioglu M. Evaluation of aqueductal CSF flow dynamics with phase contrast cine MR imaging in idiopathic intracranial hypertension patients: preliminary results. Eur Rev Med Pharmacol Sci. 2015:19(18):3475-9.

22. Donaldson JO. Cerebrospinal fluid hypersecretion in pseudotumor cerebri. Trans Am Neurol Assoc. 1979;104:196-8.

23. Gideon P, Sorensen PS, Thomsen C, Stahlberg F, Gjerris F, Henriksen O. Assessment of CSF dynamics and venous flow in the superior sagittal sinus by MRI in idiopathic intracranial hypertension: a preliminary study. Neuroradiology. 1994;36(5):350-4.

24. Janny P, Chazal J, Colnet G, Irthum B, Georget AM. Benign intracranial hypertension and disorders of CSF absorption. Surg Neurol. 1981;15(3):168-74.

25. Malm J, Kristensen B, Markgren P, Ekstedt J. CSF hydrodynamics in idiopathic intracranial hypertension: a long-term study. Neurology. 1992;42(4):851-8

26. Orefice G, Celentano L, Scaglione M, Davoli M, Striano S. Radioisotopic cisternography in benign intracranial hypertension of young obese women. A seven-case study and pathogenetic suggestions. Acta Neurol. 1992;14(1):39-50.

27. Eide PK, Eidsvaag VA, Nagelhus EA, Hansson HA. Cortical astrogliosis and increased perivascular aquaporin-4 in idiopathic intracranial hypertension. Brain Res. 2016;1644:161-75.

28. Eide PK, Kerty E. Static and pulsatile intracranial pressure in idiopathic intracranial hypertension. Clin Neurol Neurosurg. 2011;113(2):123-8.

29. Hasan-Olive MM, Hansson HA, Enger R, Nagelhus EA, Eide PK. Bloodbrain barrier dysfunction in idiopathic intracranial hypertension. J Neuropathol Exp Neurol. 2019;78(9):808-18.

30. Lenfeldt N, Koskinen LO, Bergenheim AT, Malm J, Eklund A. CSF pressure assessed by lumbar puncture agrees with intracranial pressure. Neurology. 2007;68(2):155-8.

31. Behrens A, Lenfeldt N, Qvarlander S, Koskinen LO, Malm J, Eklund A. Are intracranial pressure wave amplitudes measurable through lumbar puncture? Acta Neurol Scand. 2013;127(4):233-41.

32. Eide PK, Brean A. Lumbar cerebrospinal fluid pressure waves versus intracranial pressure waves in idiopathic normal pressure hydrocephalus. Br J Neurosurg. 2006;20(6):407-14.

33. Hoffmann J, Mollan SP, Paemeleire K, Lampl C, Jensen RH, Sinclair AJ. European headache federation guideline on idiopathic intracranial hypertension. J Headache Pain. 2018;19(1):93.

34. Malm J, Jacobsson J, Birgander R, Eklund A. Reference values for CSF outflow resistance and intracranial pressure in healthy elderly. Neurology. 2011;76(10):903-9. 
35. Andresen M, Hadi A, Juhler M. Evaluation of intracranial pressure in different body postures and disease entities. Acta Neurochir Suppl. 2016;122:45-7

36. Andresen $M$, Hadi $A$, Petersen $L G$, Juhler M. Effect of postural changes on ICP in healthy and ill subjects. Acta Neurochir. 2015;157(1):109-13.

37. Andresen $M$, Juhler M. Intracranial pressure following complete removal of a small demarcated brain tumor: a model for normal intracranial pressure in humans. J Neurosurg. 2014;121(4):797-801.

38. Pedersen SH, Lilja-Cyron A, Andresen M, Juhler M. The relationship between intracranial pressure and age-chasing age-related reference values. World Neurosurg. 2018;110:e119-23.

39. Guild SJ, McBryde FD, Malpas SC. Recording of intracranial pressure in conscious rats via telemetry. J Appl Physiol. 2015;119(5):576-81.

40. Uldall M, Juhler M, Skjolding AD, Kruuse C, Jansen-Olesen I, Jensen R. A novel method for long-term monitoring of intracranial pressure in rats. J Neurosci Methods. 2014;227:1-9.

41. Kawoos U, Gu M, Lankasky J, McCarron RM, Chavko M. Effects of exposure to blast overpressure on intracranial pressure and blood-brain barrier permeability in a rat model. PLOS ONE. 2016;11(12):e0167510.

42. Botfield HF, Uldall MS, Westgate CSJ, Mitchell JL, Hagen SM, Gonzalez AM, et al. A glucagon-like peptide-1 receptor agonist reduces intracranial pressure in a rat model of hydrocephalus. Sci Transl Med. 2017. https://doi.org/10.1126/scitranslmed.aan0972.

43. Yri HM, Jensen $\mathrm{RH}$. Idiopathic intracranial hypertension is a serious condition in rapid growth. Ugeskr Laeger. 2012;174(25):1737-40.

44. Markey KA, Mollan SP, Jensen RH, Sinclair AJ. Understanding idiopathic intracranial hypertension: mechanisms, management, and future directions. Lancet Neurol. 2016;15(1):78-91.

45. Yri HM, Fagerlund B, Forchhammer HB, Jensen RH. Cognitive function in idiopathic intracranial hypertension: a prospective case-control study. BMJ Open. 2014:4(4):e004376.

46. Andrews LE, Liu GT, Ko MW. Idiopathic intracranial hypertension and obesity. Horm Res Paediatr. 2014;81(4):217-25.

47. Friesner D, Rosenman R, Lobb BM, Tanne E. Idiopathic intracranial hypertension in the USA: the role of obesity in establishing prevalence and healthcare costs. Obes Rev. 2011;12(5):e372-80.

48. Raoof N, Sharrack B, Pepper IM, Hickman SJ. The incidence and prevalence of idiopathic intracranial hypertension in Sheffield, UK. Eur J Neurol. 2011;18(10):1266-8.

49. Yri HM, Wegener M, Sander B, Jensen R. Idiopathic intracranial hypertension is not benign: a long-term outcome study. J Neurol. 2012;259(5):886-94.

50. Mulla Y, Markey KA, Woolley RL, Patel S, Mollan SP, Sinclair AJ. Headache determines quality of life in idiopathic intracranial hypertension. J Headache Pain. 2015;16:521

51. Markey KA, Uldall M, Botfield H, Cato LD, Miah MA, Hassan-Smith G, et al. Idiopathic intracranial hypertension, hormones, and 11 betahydroxysteroid dehydrogenases. J Pain Res. 2016;9:223-32.

52. O'Reilly MW, Westgate CS, Hornby C, Botfield H, Taylor AE, Markey K, et al. A unique androgen excess signature in idiopathic intracranial hypertension is linked to cerebrospinal fluid dynamics. JCl Insight. 2019. https://doi.org/10.1172/jci.insight.125348.

53. Pollak L, Zohar E, Glovinsky Y, Huna-Baron R. The laboratory profile in idiopathic intracranial hypertension. Neurol Sci. 2015;36(7):1189-95.

54. Adderley NJ, Subramanian A, Nirantharakumar K, Yiangou A, Gokhale KM, Mollan SP, et al. Association Between Idiopathic Intracranial Hypertension and Risk of Cardiovascular Diseases in Women in the United Kingdom. JAMA neurology. 2019.

55. Gonzalez-Marrero I, Hernandez-Abad LG, Castaneyra-Ruiz L, CarmonaCalero EM, Castaneyra-Perdomo A. Changes in the choroid plexuses and brain barriers associated with high blood pressure and ageing. Neurologia. 2018. https://doi.org/10.1016/j.nrl.2018.06.001.

56. Gonzalez-Marrero I, Castaneyra-Ruiz L, Gonzalez-Toledo JM, CastaneyraRuiz A, de Paz-Carmona H, Castro R, et al. High blood pressure effects on the blood to cerebrospinal fluid barrier and cerebrospinal fluid protein composition: a two-dimensional electrophoresis study in spontaneously hypertensive rats. Int J Hypertens. 2013;2013:164653.

57. Al-Sarraf H, Philip L. Effect of hypertension on the integrity of blood brain and blood CSF barriers, cerebral blood flow and CSF secretion in the rat. Brain Res. 2003;975(1-2):179-88.
58. Piper RJ, Kalyvas AV, Young AM, Hughes MA, Jamjoom AA, Fouyas IP. Interventions for idiopathic intracranial hypertension. Cochrane Database Syst Rev. 2015;(8):Cd003434.

59. Radhakrishnan K, Thacker AK, Bohlaga NH, Maloo JC, Gerryo SE. Epidemiology of idiopathic intracranial hypertension: a prospective and case-control study. J Neurol Sci. 1993;116(1):18-28.

60. Szewka AJ, Bruce BB, Newman NJ, Biousse V. Idiopathic intracranial hypertension: relation between obesity and visual outcomes. J Neuroophthalmol. 2013;33(1):4-8.

61. Sinclair AJ, Burdon MA, Nightingale PG, Ball AK, Good P, Matthews TD, et al. Low energy diet and intracranial pressure in women with idiopathic intracranial hypertension: prospective cohort study. BMJ. 2010;341:C2701.

62. Wong R, Madill SA, Pandey P, Riordan-Eva P. Idiopathic intracranial hypertension: the association between weight loss and the requirement for systemic treatment. BMC Ophthalmol. 2007;7:15.

63. Handley JD, Baruah BP, Williams DM, Horner M, Barry J, Stephens JW. Bariatric surgery as a treatment for idiopathic intracranial hypertension: a systematic review. Surg Obes Relat Dis. 2015;11(6):1396-403.

64. Okoroafor F, Karim MA, Ali A. Idiopathic intracranial hypertension and bariatric surgery: a literature review and a presentation of two cases. $\mathrm{Br}$ J Neurosurg. 2019;33(1):112-4.

65. Ottridge R, Mollan SP, Botfield H, Frew E, Ives NJ, Matthews T, et al. Randomised controlled trial of bariatric surgery versus a community weight loss programme for the sustained treatment of idiopathic intracranial hypertension: the Idiopathic Intracranial Hypertension Weight Trial (IIH:WT) protocol. BMJ Open. 2017:7(9):e017426.

66. Hornby C, Mollan SP, Botfield H, O'Reilly MW, Sinclair AJ. Metabolic concepts in idiopathic intracranial hypertension and their potential for therapeutic intervention. J Neuro-ophthalmol. 2018;38(4):522-30.

67. Kesler A, Kliper E, Shenkerman G, Stern N. Idiopathic intracranial hypertension is associated with lower body adiposity. Ophthalmology. 2010;117(1):169-74

68. Hornby C, Botfield H, O'Reilly MW, Westgate C, Mitchell J, Mollan SP, et al. Evaluating the fat distribution in idiopathic intracranial hypertension using dual-energy $X$-ray absorptiometry scanning. Neuro-ophthalmology. 2018;42(2):99-104

69. Fain JN. Release of interleukins and other inflammatory cytokines by human adipose tissue is enhanced in obesity and primarily due to the nonfat cells. Vitam Horm. 2006;74:443-77.

70. Steiner T, Weber R, Krieger D. Increased intracerebral pressure following stroke. Curr Treat Options Neurol. 2001:3(5):441-50.

71. Steiner LA, Andrews PJ. Monitoring the injured brain: ICP and CBF. Br J Anaesth. 2006;97(1):26-38.

72. Ramirez de Noriega F, Manley GT, Moscovici S, Itshayek E, Tamir I, Fellig $Y$, et al. A swine model of intracellular cerebral edema-cerebral physiology and intracranial compliance. J Clin Neurosci. 2018;58:192-9.

73. Lackner P, Vahmjanin A, Hu Q, Krafft PR, Rolland W, Zhang JH. Chronic hydrocephalus after experimental subarachnoid hemorrhage. PLoS ONE. 2013;8(7):e69571.

74. Uldall $M$, Bhatt DK, Kruuse $C$, Juhler $M$, Jansen-Olesen I, Jensen $R H$. Choroid plexus aquaporin 1 and intracranial pressure are increased in obese rats: towards an idiopathic intracranial hypertension model? Int J Obes. 2017:41(7):1141-7.

75. Chua SC Jr, White DW, Wu-Peng XS, Liu SM, Okada N, Kershaw EE, et al. Phenotype of fatty due to GIn269Pro mutation in the leptin receptor (Lepr). Diabetes. 1996:45(8):1141-3.

76. Chua SC Jr, Chung WK, Wu-Peng XS, Zhang Y, Liu SM, Tartaglia L, et al. Phenotypes of mouse diabetes and rat fatty due to mutations in the $\mathrm{OB}$ (leptin) receptor. Science. 1996;271(5251):994-6.

77. Andrews BT, Levy M, Mclntosh TK, Pitts LH. An epidural intracranial pressure monitor for experimental use in the rat. Neurol Res. 1988;10(2):123-6.

78. Silasi G, MacLellan CL, Colbourne F. Use of telemetry blood pressure transmitters to measure intracranial pressure (ICP) in freely moving rats. Curr Neurovasc Res. 2009;6(1):62-9.

79. Murtha L, McLeod D, Spratt N. Epidural intracranial pressure measurement in rats using a fiber-optic pressure transducer. J Vis Exp. 2012;62:pii 3689. https://doi.org/10.3791/3689.

80. Jallo J, Saetzler R, Mishke C, Young WF, Vasthare U, Tuma RF. A chronic model to simultaneously measure intracranial pressure, cerebral 
blood flow, and study the pial microvasculature. J Neurosci Methods. 1997;75(2):155-60.

81. Mandell EC, Zimmermann E. Continuous measurement of cerebrospinal fluid pressure in unrestrained rats. Physiol Behav. 1980;24(2):399-402

82. Jiang J, Tyssebotn I. Measurement of cerebrospinal fluid pressure in conscious rats. Undersea Hyperb Med. 1997;24(1):39-43.

83. Barth KN, Onesti ST, Krauss WE, Solomon RA. A simple and reliable technique to monitor intracranial pressure in the rat: technical note. Neurosurgery. 1992;30(1):138-40.

84. Morimoto Y, Morimoto Y, Warner DS, Pearlstein RD. Acute changes in intracranial pressure and pressure-volume index after forebrain ischemia in normoglycemic and hyperglycemic rats. Stroke. 1996;27(8):1405-9 (discussion 10).

85. Goren S, Kahveci N, Alkan T, Goren B, Korfali E. The effects of sevoflurane and isoflurane on intracranial pressure and cerebral perfusion pressure after diffuse brain injury in rats. J Neurosurg Anesthesiol. 2001;13(2):113-9.

86. Jennische E, Bergstrom T, Johansson M, Nystrom K, Tarkowski A, Hansson HA, et al. The peptide AF-16 abolishes sickness and death at experimental encephalitis by reducing increase of intracranial pressure. Brain Res. 2008;1227:189-97.

87. Shahrokhi N, Khaksari M, Soltani Z, Mahmoodi M, Nakhaee N. Effect of sex steroid hormones on brain edema, intracranial pressure, and neurologic outcomes after traumatic brain injury. Can J Physiol Pharmacol. 2010;88(4):414-21.

88. Kawoos U, Meng X, Huang SM, Rosen A, McCarron RM, Chavko M. Telemetric intracranial pressure monitoring in blast-induced traumatic brain injury. IEEE Trans Biomed Eng. 2014;61(3):841-7.

89. Williamson MR, John RF, Colbourne F. Measurement of intracranial pressure in freely moving rats. Methods Mol Biol. 2018:1717:17-25.

90. Kawoos U, McCarron RM, Chavko M. Protective effect of N-acetylcysteine amide on blast-induced increase in intracranial pressure in rats. Front Neurol. 2017;8:219.

91. Vogh BP, Godman DR. Timolol plus acetazolamide: effect on formation of cerebrospinal fluid in cats and rats. Can J Physiol Pharmacol. 1985;63(4):340-3.

92. McCarthy KD, Reed DJ. The effect of acetazolamide and furosemide on cerebrospinal fluid production and choroid plexus carbonic anhydrase activity. J Pharmacol Exp Ther. 1974;189(1):194-201.

93. Uldall M, Botfield H, Jansen-Olesen I, Sinclair A, Jensen R. Acetazolamide lowers intracranial pressure and modulates the cerebrospinal fluid secretion pathway in healthy rats. Neurosci Lett. 2017;645:33-9.

94. Malkinson TJ, Cooper KE, Veale WL. Induced changes in intracranial pressure in the anesthetized rat and rabbit. Brain Res Bull. 1985;15(3):321-8.

95. Senay LC Jr, Tolbert DL. Effect of arginine vasopressin, acetazolamide, and angiotensin II on CSF pressure at simulated altitude. Aviat Space Environ Med. 1984;55(5):370-6.

96. Scotton WJ, Botfield HF, Westgate CS, Mitchell JL, Yiangou A, Uldall MS, et al. Topiramate is more effective than acetazolamide at lowering intracranial pressure. Cephalalgia. 2018. https://doi.org/10.1177/03331 02418776455.

97. Williamson MR, Wilkinson CM, Dietrich K, Colbourne F. Acetazolamide mitigates intracranial pressure spikes without affecting functional outcome after experimental hemorrhagic stroke. Transl Stroke Res. 2019;10(4):428-39. https://doi.org/10.1007/s12975-018-0663-6.

98. Kolecka M, Ondreka N, Moritz A, Kramer M, Schmidt MJ. Effect of acetazolamide and subsequent ventriculo-peritoneal shunting on clinical signs and ventricular volumes in dogs with internal hydrocephalus. Acta Vet Scand. 2015;57:49.

99. Wall M, McDermott MP, Kieburtz KD, Corbett JJ, Feldon SE, Friedman $\mathrm{DI}$, et al. Effect of acetazolamide on visual function in patients with idiopathic intracranial hypertension and mild visual loss: the idiopathic intracranial hypertension treatment trial. JAMA. 2014;311(16):1641-51.

100. Ball AK, Howman A, Wheatley K, Burdon MA, Matthews T, Jacks AS, et al. A randomised controlled trial of treatment for idiopathic intracranial hypertension. J Neurol. 2011;258(5):874-81.

101. Hoy SM. Topiramate extended release: a review in epilepsy. CNS Drugs. 2016;30(6):559-66.
102. Parikh SK, Silberstein SD. Current status of antiepileptic drugs as preventive migraine therapy. Curr Treat Options Neurol. 2019;21(4):16.

103. Alore PL, Jay WM, Macken MP. Topiramate, pseudotumor cerebri, weight-loss and glaucoma: an ophthalmologic perspective. Semin Ophthalmol. 2006;21(1):15-7.

104. Noda M, Sonoda Y, Takemoto M, Kira R. Successful treatment with topiramate in a case of idiopathic intracranial hypertension refractory to acetazolamide. Brain Dev. 2017;49(3):207-10.

105. Palacio E, Rodero L, Pascual J. Topiramate-responsive headache due to idiopathic intracranial hypertension in Behcet syndrome. Headache. 2004;44(5):436-7.

106. Finsterer J, Foldy D, Fertl E. Topiramate resolves headache from pseudotumor cerebri. J Pain Symptom Manag. 2006:32(5):401-2.

107. Pagan FL, Restrepo L, Balish M, Patwa HS, Houff S. A new drug for an old condition? Headache. 2002:42(7):695-6.

108. Celebisoy N, Gokcay F, Sirin H, Akyurekli O. Treatment of idiopathic intracranial hypertension: topiramate vs acetazolamide, an openlabel study. Acta Neurol Scand. 2007;1 16(5):322-7.

109. Reed DJ. The effect of furosemide on cerebrospinal fluid flow in rabbits. Arch Int Pharmacodyn Ther. 1969;178(2):324-30.

110. Vogh BP, Langham MR Jr. The effect of furosemide and bumetanide on cerebrospinal fluid formation. Brain Res. 1981;221(1):171-83.

111. Melby JM, Miner LC, Reed DJ. Effect of acetazolamide and furosemide on the production and composition of cerebrospinal fluid from the cat choroid plexus. Can J Physiol Pharmacol. 1982;60(3):405-9.

112. Pollay M, Fullenwider C, Roberts PA, Stevens FA. Effect of mannitol and furosemide on blood-brain osmotic gradient and intracranial pressure. J Neurosurg. 1983;59(6):945-50.

113. Wilkinson HA, Rosenfeld SR. Furosemide and mannitol in the treatment of acute experimental intracranial hypertension. Neurosurgery. 1983:12(4):405-10

114. Li Y, Li Z, Li M, Yang Y, Wang B, Gao L, et al. Efficacy and safety of continuous micro-pump infusion of $3 \%$ hypertonic saline combined with furosemide to control elevated intracranial pressure. Med Sci Monit. 2015:21:1752-8.

115. Thenuwara K, Todd MM, Brian JE Jr. Effect of mannitol and furosemide on plasma osmolality and brain water. Anesthesiology. 2002:96(2):416-21.

116. Murphy VA, Johanson CE. Alteration of sodium transport by the choroid plexus with amiloride. Biochem Biophys Acta. 1989;979(2):187-92.

117. Murphy VA, Johanson CE. Acidosis, acetazolamide, and amiloride: effects on 22Na transfer across the blood-brain and blood-CSF barriers. J Neurochem. 1989;52(4):1058-63.

118. Plangger $\mathrm{C}$, Volkl H. Effect of amiloride and emopamil on intracranial pressure. Acta Neurol Scand. 1995;92(5):416-22.

119. House PM, Stodieck SR. Octreotide: the IIH therapy beyond weight loss, carbonic anhydrase inhibitors, lumbar punctures and surgical/ interventional treatments. Clin Neurol Neurosurg. 2016;150:181-4.

120. Panagopoulos GN, Deftereos SN, Tagaris GA, Gryllia M, Kounadi T, Karamani O, et al. Octreotide: a therapeutic option for idiopathic intracranial hypertension. Neurol Neurophysiol Neurosci. 2007;10:1.

121. Hakon J, Ruscher K, Romner B, Tomasevic G. Preservation of the blood brain barrier and cortical neuronal tissue by liraglutide, a long acting glucagon-like-1 analogue, after experimental traumatic brain injury. PLoS ONE. 2015;10(3):e0120074.

122. Povlsen GK, Johansson SE, Larsen CC, Samraj AK, Edvinsson L. Early events triggering delayed vasoconstrictor receptor upregulation and cerebral ischemia after subarachnoid hemorrhage. BMC Neurosci. 2013;14:34.

123. Zwienenberg M, Gong QZ, Lee LL, Berman RF, Lyeth BG. ICP monitoring in the rat: comparison of monitoring in the ventricle, brain parenchyma, and cisterna magna. J Neurotrauma. 1999;16(11):1095-102.

124. Roy Chowdhury U, Holman BH, Fautsch MP. A novel rat model to study the role of intracranial pressure modulation on optic neuropathies. PLoS ONE. 2013;8(12):e82151.

125. Kusaka G, Calvert JW, Smelley C, Nanda A, Zhang JH. New lumbar method for monitoring cerebrospinal fluid pressure in rats. J Neurosci Methods. 2004:135(1-2):121-7. 
126. Giulioni M, Ursino M, Gallerani M, Cavalcanti S, Paolini F, Cerisoli M, et al. Epidural pressure measurement in the rat. J Neurosurg Sci. 1986;30(4):177-81.

127. Verlooy J, Selosse P, Van Reempts J, Haseldonckx M, Borgers M. Fiberoptic intracranial pressure monitoring in rats. J Neurosci Methods. 1990;31(1):1-6.

128. Lin JS, Liu JH. Circadian variations in intracranial pressure and translaminar pressure difference in Sprague-Dawley rats. Investig Ophthalmol Vis Sci. 2010;51(11):5739-43.

\section{Publisher's Note}

Springer Nature remains neutral with regard to jurisdictional claims in published maps and institutional affiliations.
Ready to submit your research? Choose BMC and benefit from:

- fast, convenient online submission

- thorough peer review by experienced researchers in your field

- rapid publication on acceptance

- support for research data, including large and complex data types

- gold Open Access which fosters wider collaboration and increased citations

- maximum visibility for your research: over 100M website views per year

At BMC, research is always in progress.

Learn more biomedcentral.com/submissions 